\title{
Biologia de Monobia angulosa Saussure em Ninhos Armadilhas (Hymenoptera: Vespidae: Eumeninae)
}

\author{
Evandro Camillo, Carlos A. Garófalo e José C. Serrano \\ Departamento de Biologia, Faculdade de Filosofia Ciências e Letras de \\ Ribeirão Preto, USP, 14040-901, Ribeirão Preto, SP.
}

An. Soc. Entomol. Brasil 26(1): 169-175 (1997)

Biology of Monobia angulosa Saussure in Trap-Nests

(Hymenoptera: Vespidae: Eumeninae)

\begin{abstract}
Nests of Monobia angulosa Saussure were obtained at Santa Cariota Farm, Cajuru, São Paulo $(\mathrm{n}=10)$, and at the Ecological Station of Jatai, Luis Antônio, São Paulo $(n=3)$. The wasps nested in segments of bamboo canes, 158 to $194 \mathrm{~mm}$ in length and 9.5 to $15 \mathrm{~mm}$ in internal diameter. Nests con-sisted of a linear series of 1 to 6 cells, separated by mud partitions followed or not by a vestibular cell and final-closure mud plug, generally inside of the tube entrance. Intercalary cells were observed in $33.3 \%$ of nests. Brood cells were provisioned with caterpiliars and eggs were attached to the ceiling of the cells by a thin filament. More females than males were produced with females being reared of cells from the interior end of the nest. Females were larger than males, as well as the lengths of their respective cells. Natural enemies were: Chrysis intrincata Dahibom (Chrysididae), Anthrax sp. (Bombyliidae), and a Tachinidae fly. M. angulosa presented at least two generations/year, during both the hot and wet seasons.
\end{abstract}

KEY WORDS: Insecta, wasps, trap-nests, nest structure, natural enemies.

RESUMO - Ninhos de Monobia angulosa Saussure foram obtidos em ninhos armadilhas, na Fazenda Santa Cariota, Cajuru, SP $(n=10)$ e na Estação Ecológica de Jatai, Luís Antônio, SP $(n=3)$. As vespas nidificaram em gomos de bambu que variaram de 158 a $194 \mathrm{~mm}$ no comprimento e de 9,5 a $15 \mathrm{~mm}$ no diâmetro interno. Os ninhos consistiram de uma série linear de células, variando de 1 a 6, separadas por partições de barro, seguidas ou não por célula vestibular e fechamento, também de barro, construído na entrada do tubo ou mais internamente a ela. Células intercalares foram observadas em 33,3\% dos ninhos. As células de cria foram aprovisionadas com lagartas previamente paralizadas e a oviposição foi realizada no teto da célula. Foram produzidas mais fêmeas do que machos, com as fêmeas sendo criadas nas células distais. Tanto o tamanho das fêmeas como o comprimento das células de onde elas emergiram, foram significantemente maiores que os dos machos. Os inimigos naturais foram: Chrysis intrincata Dahibom (Chrysididae), Anthrax sp. (Bombyliidae) e moscas Tachinidae. M. angulosa apresentou, pelo menos, duas gerações por ano, ambas presentes na estação quente e chuvosa.

PALAVRAS-CHAVE: Insecta, vespas, ninhos armadilhas, arquitetura de ninhos inimigos naturais. 
Espécies do gênero Monobia são adaptadas a condições climáticas extremas, ocorrendo de regiões semi-áridas do centro e noroeste da Argentina e costeira desértica do Peru até as ilhas do Caribe e regiões semi-áridas do México e Estados Unidos (Willink 1982). Apesar desta ampla distribuição, a única espécie da qual a biologia de nidificação foi estudada, detalhadamente, foi $M$. quadridens (L.) a qual, constrói uma série de células (no máximo 12), em cavidades pré-existentes geralmente feitas por algumas espécies de abelhas e vespas, em madeira ou em barrancos de argila. As células são divididas por partições de barro e a entrada da cavidade é fechada com o mesmo material. Em cada célula é colocado um ovo, suspenso no teto por um curto filamento de seda, sendo aprovisionada em seguida, com lagartas de lepidópteros (Reinhart 1929, Rau 1931,1935, Frost 1944).

Estudos mais recentes, sobre M. quadridens foram realizados por Krombein (1967) em nidificações realizadas em ninhos armadilhas. Dados sobre outras espécies são conhecidos, porém de forma fragmentada. Ninhos de $M$. apicalipennis Saussure foram encontrados em ninhos abandonados de Eumeninae (Bertoni 1911) e de Sceliphron asiaticum (L.) (Fritz \& Genise 1980); Rau (1940) observou M. nigripennis Baquaert saindo de um ninho de Sceliphron.

Embora sendo a espécie mais comum do gênero, com ampla distribuição do México à Argentina (Willink 1982), nada se conhece sobre a biologia de M. angulosa Saussure. O objetivo deste trabalho é apresentar pela primeira vez, dados biológicos a partir de nidificações em ninhos armadilhas.

\section{Material e Métodos}

Áreas de Estudos, 1 - Fazenda Santa Carlota, Cajuru (=Ca), SP $\left(21^{\circ} 18^{\prime}-21^{\circ} 17^{\prime} \mathrm{S}, 47^{\circ} 12^{\prime}\right.$ $47^{\circ} 18^{\prime} \mathrm{W}$ ), onde predominam matas mesófílas semidecíduas e de galerias, cerrado (s.l.), cerradão e vários tipos de culturas, com altitudes variando de 540 a 944 m; 2- Estação Ecológica de Jatai, Luís Antônio (=LA), SP (21 ${ }^{\circ} 33^{\prime}-21^{\circ}$ $37^{\prime} \mathrm{S}, 47^{\circ} 45^{\prime}-47^{\circ} 51^{\prime} \mathrm{W}$ ), onde predominam matas de várzeas, cerrado (s. $l$.$) , cerradão e$ reflorestamentos com Pinus spp. e Eucalyptus spp., com altitudes variando de 520 a $851 \mathrm{~m}$.

De acordo com as condições climáticas (temperatura e precipitação), há duas estações nas localidades estudadas: uma estação fria e seca (maio a agosto) e uma quente e chuvosa (setembro a abril). Tanto a temperatura média mensal mais baixa $\left(14,4^{\circ} \mathrm{C}\right.$ - julho) e a mais alta $\left(26,5^{\circ}\right.$ - fevereiro), como a maior precipitação (274 mm - janeiro), ocorreram em LA. Ausência de chuvas foi observada no mês de junho, nas duas localidades.

Ninhos Armadilhas. Os ninhos armadilhas (=NA) consistiram de gomos de bambu, fechados em uma das extremidades pelo nó, com comprimentos variando de 70,0 a 250,0 $\mathrm{mm}$ e diâmetros de 6,5 a 25,0 mm. Estes NA, amarrados em grupos de 6 a 8 unidades, foram colocados horizontalmente, em prateleiras sob coberturas construídas nas localidades estudadas (450 em Ca e 250 em LA). Os NA foram inspecionados, mensalmente, durante o período de agosto/86 a julho/88 em Ca e de novembro/90 a outubro/92 em LA. Durante as inspeções, realizadas com auxílio de otoscópio, os NA completados eram retirados, identificados e transportados para o laboratório. Para cada NA retirado, um outro era colocado no mesmo lugar. No laboratório os ninhos foram abertos, para análise de seus conteúdos, medidos, fechados novamente e deixados à temperatura ambiente. Conforme os indivíduos emergiam, eram capturados, mortos sob vapor de acetato de etila, alfinetados e etiquetados. O tamanho dos indivíduos produzidos foi determinado pela largura máxima da cabeça (LMC) e comprimento da célula marginal da asa anterior (CA). Espécimens testemunhos e ninhos estão depositados na Coleção Entomológica do Departamento de Biologia, Faculdade de Filosofia, Ciências e Letras, Ribeirão Preto, USP.

\section{Resultados}

Número de Ninhos e Abundância Sazonal. M. angulosa nidificou em 10 gomos de bambu 
em Ca e em 3 em LA. De maneira geral as nidificações ocorreram de outubro a maio (exceto fevereiro), indicando a ocorrência de, pelo menos, duas gerações por ano, ambas presentes na estação mais quente e chuvosa (Fig. IA).
Arquitetura dos Ninhos. Os NA utilizados variaram de 158 a $194 \mathrm{~mm}$ no comprimento e de 9,5 a $15 \mathrm{~mm}$ no diâmetro. O espaço efetivamente ocupado pelo ninho, variou de 55 a $168,5 \mathrm{~mm}$. Em apenas três NA $(23,0 \%)$ as fêmeas construíram uma parede de barro em
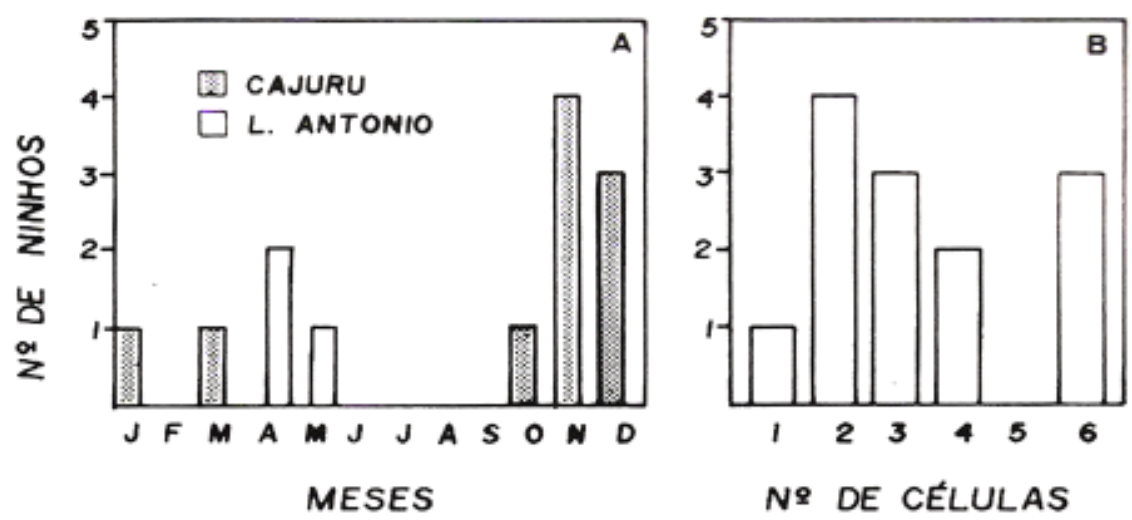

Figura 1. A - Número mensal de ninhos de Monobia angulosa, obtidos nas duas localidades estudadas, nos dois anos de coleta; B - Distribuição da frequência do número de células por ninho de Monobia angulosa.

contato com o fundo do tubo as quais, apresentaram espessuras, acentuadamente menores do que as partições celulares e os fechamentos dos ninhos (Tabela 1). Nenhum ninho foi revestido internamente com barro. O número de células de cria por ninho, construídas em série linear, variou de 1 a $6(X=3,38 \pm 1,70)$ (Fig. 1 B). A oviposição, realizada no teto

Tabela 1. Dimensões (em mm) das estruturas dos ninhos de Monobia angulosa, construídos em ninhos armadilhas.

\begin{tabular}{lrrr}
\hline Estrutura & Variação & (n) & $X \pm$ DP \\
\hline Comprimento da célula vestibular & $3,4-90,0$ & $(17)$ & $28,0 \pm 21,9$ \\
Comprimento da célula intercalar & $6,4-15,7$ & $(7)$ & $12,1 \pm 4,1$ \\
Comprimento da célula de fêmea & $17,2-35,4$ & $(14)$ & $24,0 \pm 5,5$ \\
Comprimento da célula de macho & $13,5-24,4$ & $(8)$ & $18,8 \pm 4,4$ \\
Espessura da partição celular & $1,0-4,8$ & $(43)$ & $2,1 \pm 0,9$ \\
Espessura da parede inicial & $0,5-0,6$ & $(3)$ & $0,5 \pm 0,1$ \\
Espessura do fechamento & $1,0-11,3$ & $(9)$ & $3,5 \pm 3,3$ \\
& & & \\
\hline
\end{tabular}


célula (o córion ainda estava presente quando da abertura dos ninhos), ocorreu antes do provisionamento. Cada célula foi aprovisionada com lagartas paralizadas (necessárias para o total desenvolvimento da larva), e fechadas com uma partição de barro. O comprimento das células de fêmeas foi signifïcantemente maior que o das células de machos (Mann-Whitney, $\mathrm{Z}=-2,01 ; \mathrm{P}<0,05$ ) (Tabela 1). Células intercalares foram observadas em 4 ninhos. Em Ca, em um ninho com 6 células de cria, elas ocorreram entre a segunda e terceira e entre esta e a quarta (Fig. 2) e, em outro ninho, entre as duas únicas células existentes. Em LA, em um ninho com 4 células, as intercalares ocorreram entre a primeira e segunda e entre esta e a terceira e, em outro com 6 cé- lulas, ela esteve presente entre a primeira e segunda. As partições, construídas em espiral concêntrica, apresentavam a superfície externa à célula, lisa e côncava e a interna, rugosa e convexa a qual, era revestida por uma substância sedosa e brilhante. Dentre os 12 ninhos analisados, em somente um ninho não foi observada célula vestibular enquanto que, em 6 deles ocorreu uma, em 3 duas e, em 2 três, cujas dimensões podem ser observadas na Tabela 1.

Os ninhos $(n=10)$, eram fechados por uma parede também de barro, construída após a ou as células vestibulares ou pela última partição $(n=2)$. No primeiro caso, eles apresentavam as mesmas características das partições celulares. Os fechamentos ocorreram na en-

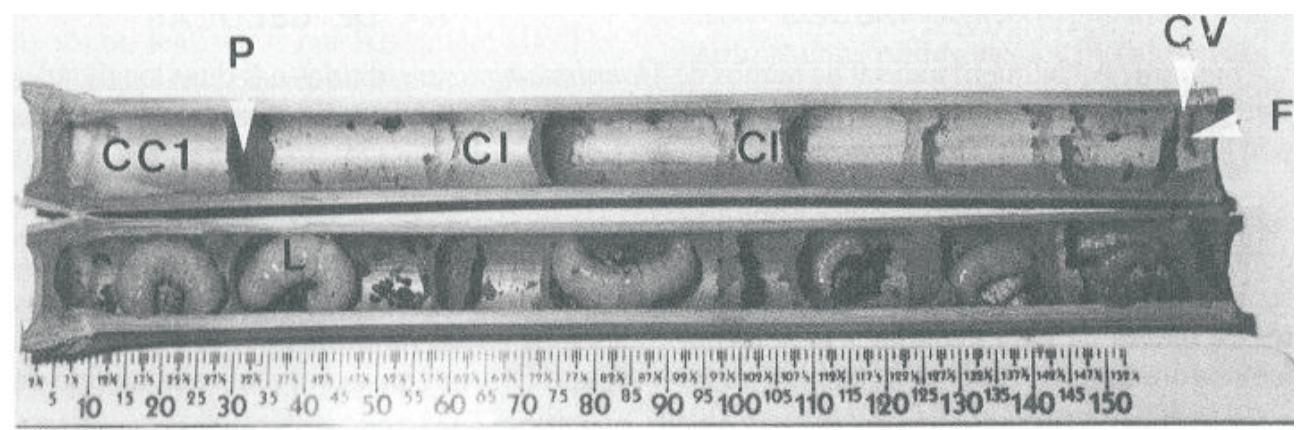

Figura 2. Ninho de Monobia angulosa contendo células de cria (CC), células intercalares (CI), partições celulares (P), célula vestibular (CV), fechamento (F) e larvas (L).

trada do tubo $(\mathrm{n}=3)$ ou mais internamente a ela $(n=9)$. Nestes casos, o comprimento do espaço vazio deixado, variou de 10 a $132 \mathrm{~mm}$. Este espaço, em um ninho, estava preenchido com terra solta não trabalhada. Fechamento composto por três elementos semelhantes às partições, unidos com barro (11,3 $\mathrm{mm}$ de espessura), foi observado ocorrer em um ninho enquanto que, em outro, uma estrutura semelhante ocorreu entre duas células vestibulares, com as espessuras dos componentes, neste caso, sendo de 1,3, 5,6 e 1,0 mm. Apesar disto, a espessura das partições e dos fechamentos não foram estatisticamente diferentes (MannWhitney, $\mathrm{Z}=0,79 ; \mathrm{P}>0,05$ ).

\section{Período de Desenvolvimento, Razão Sexual e Arranjamento das Células de Fêmeas e} Machos. A duração total de cada um dos estágios imaturos foi observada somente em uma célula de um ninho coletado imediatamente após seu fechamento. Nesse caso, o estágio de ovo durou 3 dias, o de larva e prépupa foi de 13 dias e o de pupa foi de 12 dias; 
o indivíduo produzido nessa célula foi um macho. Para outros 6 machos e 8 fêmeas a duração do estágio de pupa variou de 12 a 17 dias e de 12 a 24 dias, respectivamente. Esses indivíduos foram produzidos em ninhos construídos nos meses de novembro e dezembro. Por outro lado, em um ninho obtido em maio/ $91 \mathrm{em}$ LA as emergências ocorreram após 152 dias (macho) e 160 dias (fêmea) da coleta.

A razão sexual observada foi de 1,7 fêmeas: 1 macho ( $\mathrm{n}=22$ células), a qual foi significantemente semelhante a 1: $1(\mathrm{x} "=1,13 ; \mathrm{P}>0,05)$. Com exceção de um ninho de LA, em todos os outros de onde emergiram machos e fêmeas, as primeiras células aprovisionadas sempre produziram fêmeas.

As fêmeas com a LMC variando de 4,3 a $4,6 \mathrm{~mm}$ e o CA de 3,2 a $3,8 \mathrm{~mm}(\mathrm{n}=14)$ foram significantemente maiores que os machos, os quais apresentaram a LMC variando de 3,2 a $3,4 \mathrm{~mm}$. e o CA de 2,3 a 2,6 mm (n=8) (MannWhitney, $Z=-3,80 ; P<0,05$ e Mann-Whitney, $\mathrm{Z}=-3,54 ; \mathrm{P}<0,05$, respectivamente).

Mortalidade e Inimigos Naturais. Mor- talidade de imaturos foi observada em 38,6\% das células. Nestas, em $29,4 \%$ a mortalidade ocorreu no estágio de ovo, $17,6 \%$ no de prépupa e $17,6 \%$ no de pupa e, em $35,3 \%$ ela foi ocasionada por parasitóides. Dentre estes, emergiram moscas da família Tachinidae $(n=1)$, Chrysis intrincata Dahibom (Chrysididae) $(\mathrm{n}=1)$, Anthrax sp. (Bombyliidae) $(\mathrm{n}=1)$ e não identificados $(\mathrm{n}=3)$.

\section{Discussão}

A arquitetura dos ninhos construídos por vespas Eumeninae, que nidificam em ninhos armadilhas, apresenta uma acentuada variabilidade, mesmo dentro de uma mesma espécie. Assim, a presença de parede inicial em contato ou não com o fundo do tubo, de células intercalares e vestibulares são características que não foram observadas na totalidade dos ninhos de Pachodynerus aestraeus Cameron, $P$. erynnis Lepeletier, $M$. quadridens
(Krombein 1967), P. nasidens Latreille (Lopes et al. 1978, Jayasingh \& Taffe 1982, Dália Vecchia 1988), Rhynchium atrissimum van der Vech (Reyes 1983) e de M. angulosa, neste trabalho.

As espessuras das paredes iniciais, partições e fechamentos dos ninhos das espécies de Eumeninae estudadas por Krombein (1967), Danks (1971), Jayasingh \& Taffe (1982), Reyes (1983) e Dália Vecchia (1988), apresentaram também, uma grande variação. Em $P$. nasidens (Dália Vecchia 1988) a espessura das partições foi menor do que aquela das paredes iniciais e fechamentos. Krombein (1967) observou em ninhos de $M$. quadridens que, apesar de algumas paredes iniciais terem atingido até 10,0 $\mathrm{mm}$ de espessura, no geral, os fechamentos foram mais espessos do que elas e partições. Em M. angulosa estas estruturas apresentaram espessuras semelhantes porém, maiores que aquelas das paredes iniciais.

A utilização pelas fêmeas de $M$. quadridens, de terra aglutinada ou barro para a construção dos ninhos, ocorreu em duas das três localidades estudadas por Krombein (1967). Na outra, como também observado para $M$. angulosa o material utilizado foi barro.

Apesar de Rau (1931) ter observado em ninhos de Monobia sp., a presença de célula intercalar após cada célula de cria, Frost (1944) não encontrou tal estrutura em ninhos de espécies do mesmo gênero, quando construídos em tubos de vidro. M quadridens (Krombein 1967) e M. angulosa, aqui estudada, apresentaram células intercalares porém, em menor número do que as de cria. A presença de 2 ou 3 células intercalares após uma célula de cria, observadas por Krombein (1967) em dois ninhos de M. quadridens, não foi observada neste trabalho.

A presença de célula intercalar seria uma característica dos ninhos de vespas mais primitivas as quais, construiam em seus ninhos apenas uma célula de cria e uma vestibular. Durante a evolução, outras espécies passaram a construir várias células de cria em série linear, intercaladas com células vazias. Poste- 
riormente, as células intercalares foram eliminadas de tal forma que poucos indivíduos, de um número restrito de espécies, ainda apresentam o comportamento de construção deste tipo de estrutura (Krombein 1967). De acordo com este autor, a maioria dos ninhos de $\mathrm{M}$ quadridens apresentou célula vestibular podendo estas, estarem divididas em compartimentos, por duas ou três partições o que, também foi observado neste trabalho, em $M$. angulosa.

$O$ comprimento das células de cria é também uma característica variável, tanto entre as espécies como para uma mesma espécie ou em relação ao sexo dos indivíduos produzidos. Rau (1932) em Odynerus foraminatus Saussure, Krombein (1967) em Ancistrocerus antilope Panzer e Jayasingh (1980) em P. nasidens observaram que as células de fêmeas eram maiores que a dos machos, como também observado neste trabalho, enquanto que Dália Vecchia (1988), em ninhos com 84 mm de comprimento, obteve o inverso para $P$. nasidens.

Nos Eumeninae, a oviposição, realizada no teto da célula, ocorre antes do aprovisionamento ou seja, logo após a fêmea ter terminado a construção da mesma (Spradbery 1973, Krombein 1978, Jayasingh \& Taffe 1982, Reyes 1983). Em M. angulosa a localização do ovo é a mesma, ocorrendo também a oviposição antes do aprovisionamento. Observações discordantes foram relatadas por Isely (1913, in Spradbery 1973) para algumas espécies norte americanas cujas fêmeas ovipositaram após a colocação de algumas presas na célula e, por Iwata (1976) que observou em Pseumenes, o aprovisionamento de células antes das oviposições.

A duração dos estágios imaturos, nos Eumeninae, variou muito entre as localidades estudadas por vários autores, porém, os resultados obtidos em Monobia sp. (Rau \& Rau 1918) (34 dias) e em M. quadridens (Krombein 1967) (36-37 dias para as fêmeas e 26 dias para os machos) em uma das localidades estudadas (Florida-Estados Unidos), foram aqueles que mais se assemelharam aos obtidos em angulosa. A duração ( 52-56 dias) obtida por Frost (1944), em ninhos de Monobia sp., segundo Krombein (1967) talvez seja devida a alta umidade no interior dos tubos de vidro, utilizados como ninhos armadilhas. A ocorrência de diapausa pré-pupal observada em um ninho de $M$. angulosa mostra que esta espécie possui duas estratégias diferentes, em resposta às condições climáticas adversas. Uma delas é permanecer por um longo período de tempo no estágio de pré-pupa e, a outra, no estágio de adulto. Este último fato pode ser observado pois, apesar de terem ocorrido emergências em maio, novas nidificações somente tiveram início em outubro. $\mathrm{O}$ mesmo fato foi observado em Ribeirão Preto, em $\mathrm{Po}$ dium denticulatum Smith e em Tetrapedia curvitarsis Friese em Ca (E. Camillo et al. não publicado).

Dentre os parasitoides emergidos em ninhos de M. quadridens (Krombein 1967), somente indivíduos do gênero Anthrax sp. e da família Chrysididae (também observado em Monobia sp. por Rau 1922) estiveram presentes dentre aqueles encontrados em $M$. angulosa.

\section{Agradecimentos}

À FINEP e ao CNPq pelo suporte financeiro. Ao Instituto Florestal por permitir o desenvolvimento do presente projeto na Estação Ecológica de Jatai, Luís Antônio, SP, e aos proprietários da Fazenda Santa Carlota, Cajuru, SP, por permitirem o acesso à propriedade. Ao Dr. António C. Zanatto pelas facilidades concedidas durante o projeto em Luís Antônio. Somos gratos também a A. S. Menke (Sistematic Entomology Laboratory, USDA, Washington-USA) pela identificação de $\mathrm{Mo}$ nobia angulosa.

\section{Literatura Citada}

Bertoni, A.W. 1911. Contribuición a Ia biologia de las avispas y abejas del Paraguay (Hymenoptera). An. Mus. Nac. Hist. Nat. B. Aires 22: 97-146. 
Dalla Vecchia, M.B.B. 1988. Aspectos biológicos de Pachodynerus nasidens (Hymenoptera: Eumenidae) em ninhos armadilhas. Tese de mestrado. F.F.C.L.R.P. - USP. Ribeirão Preto, 128p.

Danks, J. V. 1971. Biology of some stemnesting aculeate Hymenoptera. Trans. Roy. Entomol. Soc. London, 122: 323-399.

Fritz, M.A. \& J.F. Genise. 1980. Notas sobre nidos de barro de Sphecidae (Hymenoptera). Constructores, inquilinos, parasitoides, cleptoparásitos y detritivoros. Rev. Soc. Entomol, Arg. 39: 67-81.

Frost, S.W. 1944. Notes on the habits of Monobia quadridens (Linn.). Entomol. News 55:10-14.

Jayasingh, D.B. 1980. A new hypothesis on cell provisioning in solitary wasps. Biol. J. Linn. Soc. 13: 167-170.

Jayasingh, D.B.\& C.A.Taffe. 1982. The biology of the eumenid mud-wasp Pachodynerus nasidens in trap-nests. Ecol. Entomol. 7:283-289.

Krombein. K. V. 1967. Trap-nesting wasps and bees: Life histories, nests and associates. Smithsonian Press, Washington D.C.569p.

Krombein, K.V. 1978. Biosystematic studies of ceylonese wasps III. Life history, nests and associates of Paraleptomenes mephitis (Cameron) (Hymenoptera: Eumenidae). J. Kansas Entomol. Soc. 1: 721-734.

\section{Lopes, J.R.; C.A. Garofalo \& J.C. Serrano.}

1978. Observações preliminares sobre a bionomia de Pachodynerus nasidens (Hymenoptera: Eumenidae). Ciência e Cultura 30: 595 .
Rau, P. 1922. Ecological and behavior notes on Missouri insects. Trans. Acad. Sci. St.Louis 24: 1-71.

Rau, P. 1931. The cocooning habit of the wasp Monobia quadridens. Bull. Brooklyn Entomol. Soc. 26:4-6.

Rau, P. 1932. The relation of the size of the cell to the sex of the wasp in Odynerus foraminatus Sauss.. Entomol. News 43: 119-121.

Rau, P. 1935. The courtship and mating of the wasp, Monobia quadridens (Hym. Vespidae). Ent. News 46: 57-58.

Rau, P. 1940. Some mud-daubing wasp of México and their parasites. Ann. Entomol. Soc. Am. 33: 590-595.

Rau, P. \& N. Rau. 1918. Wasp studies afield. Princeton, 372p.

Reinhart, E. 1929. The Witchery of wasps. The Century Co. NewYork, 291 p.

Reyes, S.G. 1983. Biological notes on Rhynchium atrissimum van der Vech (Hymenoptera: Eumenidae). Philipp. J. Biol. 12: 91-99.

Spradbery,J.P. 1973. Wasps - An account of the biology and natural history of solitary and social wasps. Sidgwich \& Jackson, London,408p.

Willink, A. 1982. Revision de los gêneros Montezumia Saussure y Monobia Saussure. Bol. Acad. Nac. de Ciências 55. Cordoba. Argentina, $321 \mathrm{p}$.

Recebido em 22/07/96. Aceito em 20/03/97. 